\title{
Asymmetric Attention and Stock Returns
}

\author{
Jordi Mondria* \\ Thomas $\mathrm{Wu}^{\dagger}$ \\ University of Toronto \\ UC Santa Cruz \\ PRELIMINARY DRAFT
}

January 2011

\begin{abstract}
We study the asset pricing implications of attention allocation theories. These theories allow us to predict the arrival of private information by observing investors' behavior. Specifically, attention allocation theories suggest that the arrival of private news to local investors lead to an increase in asymmetric attention to stocks between local and nonlocal investors. We construct a measure of asymmetric attention based on aggregate search volume in Google. We find that firms receiving an increase in asymmetric attention earn higher returns, even after controlling for size, book-to-market, momentum and liquidity factors. We find this effect to be stronger among illiquid stocks and stocks headquartered in remote locations. Our results provide direct support for attention allocation theories.

Keywords: Attention Allocation, Asymmetric Information, Stock Returns, Geography. JEL Codes: G12, G14, D82.
\end{abstract}

\footnotetext{
${ }^{*}$ Economics Department. 150 St. George St., Toronto, ON, M5S 3G7. E-mail: jordi.mondria@utoronto.ca.

${ }^{\dagger}$ Economics Department, 465 E2 Building, Santa Cruz, CA 95064. E-mail: thomaswu@ucsc.edu.
} 


\section{Introduction}

Attention allocation theories (see Van Nieuwerburgh and Veldkamp, 2009 and Mondria and $\mathrm{Wu}, 2010)$ recently rationalized why investors hold under-diversified portfolios. These theories help resolve the apparent contradiction between the substantial benefits from portfolio diversification and the small amount of nonlocal equity held by investors. In their framework, investors face an attention allocation decision before choosing their asset holdings. Specifically, investors choose what information they want to learn about local and nonlocal stocks. Assuming investors have an informational advantage that makes local investment slightly less risky, the authors show that investors process mostly information about local assets and, compared to the market portfolio, hold a greater proportion of these assets. In other words, investors do not only hold more local assets because local information is cheaper or they have large exogenous information asymmetries, but portfolios are locally biased because investors choose to allocate more attention to local stocks.

In this paper, we study the asset pricing implications of attention allocation theories. Following, Barber and Odean (2008), we conjecture that investors allocate attention to stocks only when making buying decisions, but not when selling. Under attention allocation theories, when investors receive private news about local companies, it is optimal for them to start processing more public information about these local firms. Everything else equal, the information asymmetry between local and nonlocal investors gets endogenously magnified. As a result there is an increase in the buying pressure by locals and stock prices increase over a period of time. Hence, if we observe local investors processing more public information about local stocks, we can then infer that local investors have received private information and stock prices will increase.

The challenge when testing attention allocation theories is to find direct measures of effort spent in processing information. Previous research used different indirect measures of attention such as advertising expenses (i.e., Lou, 2008), media coverage (i.e., Fang and Peress, 2009), abnormal trading volume (i.e., Hou, Peng, and Xiong, 2008), extreme returns (i.e., Barber and Odean, 2008) and the state of the business cycle (Kacperczyk, Van Nieuwerburgh and 
Veldkamp, 2010). Recent work by Mondria, Wu and Zhang (2010) and Da, Engelberg and Gao (2010) overcame this challenge by using measures of aggregate search frequency from AOL and Google search engines respectively as direct measures of attention. As argued by Da, Engelberg and Gao (2010), if a search engine user is searching for a company ticker, it is highly likely that this user is interested in financial information about the company. However, the main challenge associated with evaluating current attention allocation theories is in distinguishing the effort exerted by locals relative to nonlocals in processing information.

In this paper, we obtain direct measures of effort exerted in processing information about a company by local and nonlocal investors by using a new feature of Google Insights for Search that allows us to distinguish the location where searches are made by U.S. state. We document that on average investors search twice as much information about local stocks than nonlocal stocks. There is a large literature analyzing the role of geography in finance initiated by Coval and Moskowitz $(1999,2001)$ that provides evidence in favor of investors having local information advantages. Our findings suggest that part of this local information advantage is endogenous. According to attention allocation theories, even if the public information acquisition costs are the same for locals and nonlocals, investors choose to process more information about local stocks if there is a small initial information asymmetry. It is difficult to argue that our evidence can only be explained by differences in costs to information acquisition by locals and nonlocals since we focus on information that is publicly available. Overall, we believe this finding provides direct support for attention allocation theories.

After having established direct support for attention allocation theories, we study its asset pricing implications. We construct a measure of asymmetric attention that captures the attention allocated to a stock by locals relative to nonlocals. An increase in asymmetric attention means that local investors are allocating more attention in learning about public information from local stocks than nonlocal investors. Attention allocation theories suggest that this is due to the arrival of private news to locals, which leads them to buy local stocks and, in turn, generates an increase in asset prices. We focus on stocks included in the S\&P 500 between January 2004 and December 2009. A portfolio that goes long on stocks with high asymmetric 
attention and short on stocks with no asymmetric attention has a Jensen's alpha of 46 bps per month that is statistically and economically significant. We find our results to be robust to different statistical techniques such as Fama and MacBeth (1973) and panel regressions. Our results are also robust to DGTW characteristic-adjusted abnormal returns, which are constructed using the method developed by Daniel, Grinblatt, Titman, and Wermers (1997).

Our asymmetric attention effect on asset prices is persistent due to the impedimentsto-trade hypothesis. In particular, we find that the return differential between the highasymmetry and no-asymmetry portfolios is more pronounced for the most illiquid stocks. We finally corroborate our hypothesis that high asymmetric attention is related to the arrival of private news. We find that the return differential between the high-asymmetry and noasymmetry portfolios is more pronounced for stocks located in more remote places where exogenous asymmetric information is more accentuated. Specifically, we find a Jensen's alpha of 82 bps per month for the long-short portfolio sorted by asymmetric attention for stocks located in remote areas.

Our paper contributes to the literature that supports a link between proximity and stock market participants behavior. Coval and Moskowitz (1999, 2001) initiated this literature by analyzing the role of geography in the context of mutual fund managers. They find managers located in remote areas earn higher returns in local stocks than managers located in large cities. They argue proximity is a proxy for information precision or quality. There is a large and growing literature studying the importance of geography in finance and economics. Malloy (2005) and Bae, Stulz, Tan (2008) study the link between geographic proximity and analyst behavior. Portes and Rey (2005) document a close relationship between international capital flows and distance between countries. Ivkovic and Weisbenner (2005) show that individual investors tilt their portfolio towards local assets and earn additional returns in those local assets. Grote and Umber (2006) and Uysal, Kedia and Panchapagesan (2008) provide evidence linking proximity and success in mergers and acquisitions deals. Our results are different from the geography literature. One particular implication from Coval and Moskowitz $(1999,2001)$ and Ivkovic and Weisbenner (2005) is that companies located in more remote areas suffer from 
more information asymmetries and, thus, should earn higher returns. In our paper, we focus on the timing of the arrival of asymmetric information and form portfolios accordingly. We use attention allocation theories to predict when those firms located in remote areas actually suffer from asymmetric information.

The rest of the paper is organized as follows. Section 2 describes our data sources, explains how we construct the asymmetric attention variable and provides descriptive summary statistics. Section 3 provides empirical evidence in favor of the asset pricing implications of the attention allocation theories. Section 4 studies the link between asymmetric attention and liquidity. Section 5 examines the relation between asymmetric attention and the arrival of private information. Section 6 concludes.

\section{Data}

Our sample consists of the constituents of the S\&P 500 that are headquartered in United States. The data used to construct our measures of attention allocation is downloaded from Google Insights for Search. ${ }^{1}$ Stock prices, return, volume, market capitalization and related variables are obtained from CRSP; accounting data and headquarters location are obtained from Compustat; state level data such as population and GDP are obtained from U.S. Census Bureau.

\subsection{Aggregate Search Volume}

We obtain aggregate search volume data from Google search engine users using Google Insights for Search. While Google Insights for Search and Google Trends (previously used database by Da, Engelberg and Gao, 2010) use the same data, Insights for Search is geared towards users (such as researchers or advertisers) who may find some of its advanced features more useful for their purposes. We are interested in filtering data at the national and state level, which Google Trends does not allow. Google Insights for Search uses IP address information to make an educated guess about where search queries originated. The data ranges from January 2004

\footnotetext{
${ }^{1}$ http://www.google.com/insights/search/
} 
to December 2009 and contains the monthly search volume index for any search term. The search volume index (SVI) for a particular term is the query share of that term for a given location and period of time normalized by the highest query share of that term over the timeseries. A web search query is the exact phrase that a user types into the search engine. Query share for a particular term is the ratio between the number of queries for that term and the total number of queries at a given time and location. In less technical terms, Google calculates the search traffic for a particular term as the number of searches of this term relative to the total number of searches on Google for a given location and period of time. Google then constructs the search volume index (SVI) for a search term by normalizing the search traffic for a particular term by the highest search traffic for that term over the time-series. Hence, the SVI data ranges from 0 to 100. A decrease in SVI does not necessarily imply a reduction in the absolute number of web search queries for a particular term. A decrease in SVI implies that the popularity (or query share) of a particular term is decreasing.

We obtain monthly SVI data for every stock headquartered in U.S. included in the S\&P 500 between January 2004 and December 2009. We collect data for all stocks ever included in the index during our sampling period and exclude those observations where prices are below $\$ 5$ to avoid microstructure related biases. Our sample consists of 644 stocks. Following Da, Engelberg and Gao (2010), we collect SVI data for a stock using its ticker. If a search engine user is searching for a company ticker, it is highly likely that this user is interested in financial information about the company. Furthermore, using ticker search volume makes our sample construction less subjective than if we used the company's name. We then filter the SVI data for each company's ticker by location. Specifically, we filter SVI data for each stock by i) national searches or users located in U.S. and $i$ ) local searches or users located in the state where the company is headquartered.

\subsection{Local vs. National SVI}

When collecting SVI data, we obtain national and local searches for a given ticker simultaneously. This feature of Google Insights for Search normalizes both times series by the same 
constant, which is the highest query share of the ticker between both time-series. We can then compare the popularity of a company's ticker between national and local searches. We define the variable asymmetric searches as local searches/national searches. An asymmetric searches larger than one implies that investors search more frequently local than nonlocal stocks. Although portfolios based on this asymmetric searches variable will turn out not to generate excess returns, we still find useful to present its summary statistics and its relation to firm characteristics. This variable is of special interest for attention allocation theories. Recent work from van Nieuwerburgh and Veldkamp (2009) and Mondria and Wu (2010) suggest that, in the presence of a limited attention constraint and a small local information advantage, it is optimal for investors to allocate most of their limited attention to local stocks. This implies that the variable asymmetric searches should be larger than one.

Panel A in Table 1 presents the summary statistics for our local searches, national searches and asymmetric searches variables. We are able to obtain valid local SVI data for 486 stocks and national SVI data for 513 stocks. Unfortunately, as in Da, Engelberg and Gao (2010), Insights for Search does not return valid SVI data for some tickers. Insights for Search only returns data for terms that have a significant amount of search volume. The mean SVI for national searches is 39.3 , while for local searches is 54.6. This suggests that investors process more information about local stocks than nonlocal stocks. This Panel also shows significant variation in SVI data for both national and local searches. The standard deviation for national and local searches is 24.9 and 21.4 respectively.

A key component of this paper is the variable asymmetric searches. The average asymmetric searches is 2.3. This implies that on average investors search twice as much information about local stocks than nonlocal stocks. The median asymmetric searches, however, is 1.24, which implies that investors process $25 \%$ more information about local companies than nonlocal companies. The distribution of asymmetric searches has a positive skew. This means that there are some stocks in the S\&P 500 that have much less interest for the average U.S. investor than for the average local investor. This evidence shows that investors process more information about local stocks than nonlocal stocks. It also provides support to the large and 
growing literature studying the importance of geography in finance (Bae, Stulz, Tan, 2008, Coval and Moskowitz, 1999, 2001, Ivkovic and Weisbenner, 2005, Malloy, 2005, Portes and Rey, 2005). These projects conjectured that investors have access to local private information and analyzed the role of geography in different finance settings. Our evidence does not only suggest that investors have local private information, but also that investors choose to process more public information about local firms. It is difficult to argue that this evidence can be explained by differences in costs to information acquisition by locals and nonlocals since all information is publicly available. According to attention allocation theories, even if the public information acquisition costs are the same for locals and nonlocals, investors choose to process more information about local stocks if there is a small initial exogenous information asymmetry. Our evidence provides direct support for attention allocation theories.

Panel B in Table 1 presents the relation of our asymmetric searches variable to the following firm characteristics: $i$ ) ME is the market capitalization in the previous month $(t-1)$; ii) $\mathrm{BE} / \mathrm{ME}$ is the book-to-market value of equity, where the book value, which is calculated according to Davis, Fama, and French (2000), is divided by the previous month market capitalization; iii) RET is the return of the stock during the month; iv) RET[t-13,t-2] is the cumulative return of the stock between t-13 and t-2; v) AMIHUD is the liquidity measure constructed according Amihud (2002); vi) SPREAD is the proportional quoted bid-ask spread; vii) VOLATILITY is the standard deviation of the daily stock returns of the current month; viii) $\triangle$ TURNOVER is the difference in the natural logarithm of stock turnover between $t$ and $t-1$. Each month, we divide our sample in five quintiles according to the asymmetric searches variable, where the first quintile consists of stocks with the lowest asymmetric searches. Firms in the first quintile of asymmetric searches are firms with relative national interest, while firms in the fifth quintile are firms with relative local interest. We then calculate the averages of the firm characteristics for each of the five quintiles. The average asymmetric searches for firms with national interest (first quintile) and firms with local interest (fifth quintile) is 0.76 and 6.43 respectively. We expected small firms to have higher local interest, but there is no relation between size and asymmetric searches. A potential explanation might be that big 
firms have more employees who hold local stocks. It is also interesting to note that firms with higher cumulative returns (RET[t-13,t-2]) have less asymmetry between local and national SVI. The Amihud illiquidity measure is monotonically increasing with asymmetric searches. Firms with national interest are more liquid than firms with local interest. However, there is no clear relationship of volatility, spreads, turnover or book-to-market ratio with respect to asymmetric searches.

\subsection{Attention Allocation}

We construct our measures of attention allocated to a stock based on the search volume index of its ticker. We measure the absolute attention to a stock by an average U.S. investor or national attention as the abnormal SVI to the company's ticker filtered by searches located in U.S. We define abnormal SVI as (log) SVI during the current month minus the (log) median SVI during the previous quarter (previous three months). We measure absolute attention to a stock by a local investor or local attention as the abnormal SVI to the company's ticker filtered by searches located in the state where the company is headquartered. We measure asymmetric attention as the abnormal SVI by locals minus abnormal SVI by average U.S. investor. In sum, we proxy attention by abnormal search volume relative to previous quarter.

Panel A in Table 2 presents the summary statistics for our local attention, national attention and asymmetric attention variables. The mean and median of these variables is around zero. These measures have a significant variation with a standard deviation of $0.25,0.21$ and 0.21 for local attention, national attention and asymmetric attention respectively.

Panel B in Table 2 exhibits the relation of our asymmetric attention variable to several firm characteristics. Each month, we divide our sample in five quintiles according to the asymmetric attention variable, where the first quintile consists of stocks with the lowest asymmetric attention. Observations in the first quintile reflect an increase in the attention of the stock by the average U.S. investor, while observations in the fifth quintile reflect an increase in the attention allocated to the stock by local investors. The distribution of the asymmetric attention variable is quite symmetric relative to the right skewness observed for asymmetric 
searches. From the univariate analysis, we can observe that there is no monotonic relation of asymmetric attention with any relevant firm characteristic.

\section{Asymmetric Attention and Stock Returns}

We investigate the hypothesis that stocks with more asymmetric attention between local and nonlocal investors earn higher future returns. Our hypothesis is based on two different theories of attention allocation: i) Van Nieuwerburgh and Veldkamp (2009) and Mondria and $\mathrm{Wu}(2010)$ demonstrate that investors choose to process public information about stocks when they receive private news. Following the literature on finance and geography, we conjecture that investors have an initial local and exogenous information advantage. ii) Barber and Odean (2008) argue that attention is a major determinant to understand investors' buying decisions but not selling decisions. Following these two theories, we interpret an increase in asymmetric attention as the arrival of private news that leads local investors, who are considering buying the stock, to process more public information about local stocks. This implies that the information asymmetry between locals and nonlocals gets endogenously magnified. Thus, we hypothesize that the increase in asymmetric attention will lead local investors to buy local stocks that will then earn temporarily higher returns until local information is spread at the national level. ${ }^{2}$

We use three different approaches to investigate the relationship between asymmetric attention and future stock returns. First, we run Fama and MacBeth (1973) cross-sectional regressions. Second, we use dynamic panel regressions, where we include time and country fixed effects and cluster-robust standard errors to control for unobserved heterogeneity. Third, we form long-short portfolios sorted by asymmetric attention.

\subsection{Cross-sectional Regressions}

We first study the relation between asymmetric attention and future stock returns for the S\&P 500 stocks included in our sample. We run Fama and MacBeth (1973) cross-sectional

\footnotetext{
${ }^{2}$ This argument does not apply to selling stocks. According to Barber and Odean (2008), attention is only a major determinant of buying decisions.
} 
regressions each month from January 2004 to December 2009. These results are reported in Table 3. In the first four regressions, the dependent variable is the DGTW characteristicadjusted abnormal returns from month $t+1$, which are constructed using the method developed by Daniel, Grinblatt, Titman, and Wermers (1997). The DGTW abnormal returns control for the effects of size, book-to-market ratio and momentum. All regressions control for the following firm characteristics defined above: $\log (\mathrm{ME})$ is the natural logarithm of the market capitalization in month $t$; $\log (\mathrm{BE} / \mathrm{ME})$ is the natural logarithm of the book-to-market value of equity, where the book value, which is calculated according to Davis, Fama, and French (2000), is divided by the previous month market capitalization; RET is the return of the stock during month $t$; RET[t-13,t-2] is the cumulative return of the stock between $t-13$ and $t-2$; AMIHUD is the liquidity measure constructed according to Amihud (2002) from month $t$; SPREAD is the proportional quoted bid-ask spread in month $t$; VOLATILITY is the standard deviation of the daily stock returns of the current month $t$; $\triangle$ TURNOVER is the difference in the natural logarithm of stock turnover between $t$ and $t-1$.

In the first regression of Table 3, as previously announced, we find no effect of asymmetric searches on future stock returns. The difference in levels between local and national SVI does not generate a coefficient that is statistically significant different than zero. In the second regression, we try to replicate the results from Da, Engelberg and Gao (2010) at the monthly frequency. We use national attention as independent variable. We find no evidence of an empirical relation between national attention and future DGTW abnormal stock returns. Da, Engelberg and Gao (2010) argued that national attention has an effect in the first two weeks of the month, but the effect is reversed at the end of the month. In the third regression, we use national attention and local attention as independent variables. As before, the coefficient for national attention is not significant. The local attention coefficient is economically and statistically significant. A one standard deviation increase in local attention leads to an increase in future DGTW abnormal returns by 18.2 basis points (bps hereafter). However, we will show in the next section below that the relation between our local attention variable and future stock returns is not robust to other approaches. In the fourth regression, we study the relation 
between stock returns and asymmetric attention. The asymmetric attention coefficient is also economically and statistically significant. A one standard deviation increase in asymmetric attention is associated with an increase in the next-month DGTW abnormal stock returns of 13.2 bps. Another way to quantify the economic significance of the asymmetric attention coefficient is to obtain the difference between the first and fifth quintile of asymmetric attention from Panel B in Table 2 and multiply it by the regression coefficient. Everything else equal, observations with high asymmetric attention earn future DGTW abnormal stock returns that are 34.6 bps higher than observations with low asymmetric attention. We will show in the following sections that the relation between asymmetric attention and future stock returns is robust to different statistical approaches. In the fifth regression, we show that our results are robust to use future raw stock returns instead of future DGTW abnormal stock returns. We use next-month raw stock returns as dependent variable and asymmetric attention as independent variable. We find that our coefficient for asymmetric attention is also statistically and economically significant.

The significant effect of asymmetric attention is obtained after controlling for firm characteristics that previous studies found to affect stock returns. We find a negative effect of market capitalization on stock returns, although it is not consistently statistically significant. We also find a positive effect of the book-to-market ratio and the Amihud (2002) illiquidity measure on future stock returns.

In sum, our evidence shows direct supporting evidence of attention allocation theories. In the following sections, we show that our empirical evidence is robust to alternative statistical approaches.

\subsection{Panel Regressions}

In this section, we analyze the relation between asymmetric attention and future returns for the S\&P 500 stocks using panel regressions. The dependent variable in all the regressions is again the DGTW characteristic-adjusted abnormal returns from month $t+1$. We also control for the same firm characteristics as in the previous section. The results are reported in Table 4. 
We include monthly and firm fixed effects in all panel regressions. In the first four regressions, we report heteroskedasticity-robust standard errors. In the fifth regression, we report White standard errors adjusted to account for possible correlation within firm. In the first regression, we show again that there is no relation between asymmetric searches and future stock returns. In the second regression, we find no effect of national attention on future stock returns at the monthly frequency. In the third regression, as before, the coefficient for national attention is not significant. Our local attention measure is, however, economically and statistically significant. In the fourth and fifth regressions, we use asymmetric attention as independent variable. The difference between both regressions is that the fifth regression presents clustered errors by firm. In both regressions, the coefficient for asymmetric attention is statistically and economically significant. There are no differences between regressions, except for minor corrections in standard errors. According to panel regressions, a one standard deviation increase in asymmetric attention is associated with an increase in the next-month DGTW abnormal stock returns of 16.8 bps. Also, everything else equal, the difference in future DGTW abnormal stock returns between observations with high and low asymmetric attention is of 44.1 bps. All panel regression control for firm characteristics. We find a significant negative effect of size and a positive effect of the book-to-market ratio, the cumulative return and the Amihud (2002) liquidity measure on future stock returns. In summary, we find that our supporting evidence on attention allocation theories is robust to panel regressions.

\subsection{Long-Short Portfolios}

We now examine the relation between the relation between asymmetric attention and future returns for the S\&P 500 stocks forming equal-weighted and value weighted portfolios sorted by asymmetric attention. Each month, we sort stocks into high-asymmetry and no-asymmetry based on asymmetric attention. We then form three different portfolios: i) high-asymmetry portfolio consists of stocks that in a given month have an asymmetric attention above the 80th percentile; ii) no-asymmetry portfolio consists of stocks that in a given month are not included 
in the high-asymmetry portfolio; ${ }^{3}$ iii) long-short portfolio is a zero-investment portfolio that in a given month longs high-asymmetry stocks and shorts no-asymmetry stocks. We form these three portfolios every month and calculate the following-month return for each portfolio. We then regress the time-series returns on the five-factor model that includes the three factors as in Fama and French (1993), the momentum factor as in Carhart (1997) and the liquidity factor as in Pastor and Stambaugh (2003). The market portfolio, size factor, book-to-market factor and momentum factor are downloaded from Kenneth French's website and the liquidity factor is downloaded from Robert Stambaugh's website. ${ }^{4}$ We will conclude that the difference in returns between the high-asymmetry and no-asymmetry portfolios is significant if the estimated alpha of the long-short portfolio is statistically and economically significant. In Table 5, we report both equal-weighted and value-weighted next-month excess returns over the risk free rate for each of the three portfolios. For robustness, we also report the next-month DGTW abnormal returns for each portfolio.

Panel A in Table 5 presents the factor loadings and Jensen's alpha for the equal-weighted and value-weighted returns of all stocks in the S\&P 500 in our sample period. As demonstrated by Cremers, Petajisto and Zitzewitz (2010), the five factor model generates economically and statistically significant Jensen's alphas for the S\&P 500 when using equal-weighted returns. We obtain a Jensen's alpha of 0.3 in our sample when using equal-weighted excess returns. We find, however, a zero alpha when using raw value-weighted returns. If we calculate the alphas for the 486 stocks for which we have local SVI data in our sample period, we get very similar results for both equal-weighted and value-weighted returns.

Panel B exhibits the alphas for the three portfolios sorted by asymmetric attention. As expected from Panel A, our high-asymmetry and no-asymmetry portfolios have a significant positive alpha when using equal-weighted returns. The high-asymmetry portfolio experienced an average $0.63 \%$ following-month excess return, while the no-asymmetry portfolio had an average $0.21 \%$ following-month excess return. The long-short portfolio shows a $42 \mathrm{bps}$ difference between high-asymmetry and no-asymmetry portfolios that is statistically and economically

\footnotetext{
${ }^{3}$ Stocks below the the 80th percentile of asymmetric attention have almost no difference between national and local attention as is observed in Panel B of Table 2.

${ }^{4}$ Liquidity factors are only available until 2008.
} 
significant when using equal-weighted excess returns. In contrast, the no-asymmetry portfolio when using value-weighted returns exhibits a zero alpha, while the high-asymmetry portfolio obtains a $0.46 \%$ average next-month excess return. The long-short portfolio produces a 46 bps next-month return that is statistically and economically significant. Regarding riskadjusted returns, we obtain the following statistically significant alphas $0.15,0.4$ and 0.25 for the no-asymmetry, high-asymmetry and long-short portfolios respectively when using equalweighted DGTW returns. Similarly, we get alphas of -0.01, 0.36 and 0.37 for the three portfolios respectively when using value-weighted DGTW returns. The difference in magnitude for equal-weighted and value weighted returns between the high-asymmetry and no-asymmetry portfolios is similar to the one obtained under panel and cross-section regressions.

Panel C presents the Jensen's alphas for three portfolios sorted by local attention. The high-local portfolio includes stocks that have a local attention above the 80th percentile in a given month, while the no-local portfolio includes those below the 80 th percentile. The longshort-local portfolio is constructed by having a long position in high-local stocks and short position in no-local stocks. We then calculate the following-month returns for each of these three portfolios. Under equal weighted excess returns, the high-local portfolio experienced an average $0.57 \%$ following-month excess return, while the no-asymmetry portfolio had an average $0.23 \%$ following-month excess return. However, the long-short portfolio has an alpha that is not statistically different from zero. Under value weighted returns, none of the portfolios produces a Jensen's alpha statistically different from zero. The results for risk-adjusted returns are similar to those with raw excess returns. Overall, the relation between local attention and future returns for the S\&P 500 stocks is not robust to different statistical approaches.

In sum, the previous three sections show a robust relation between asymmetric attention and future returns for the S\&P 500 stocks. Stocks with more asymmetric attention between local and nonlocal investors earn higher future returns. Our results suggest that is not local attention by itself that matters to earn higher future returns, but the difference between local attention and national attention. 


\subsection{Robustness}

We now examine the robustness of our results to the characteristics of the state where the firm is headquartered. It might be that our results are driven by stocks headquartered in a particular state. In Table 6, we introduce additional variables that aim to control for state fixed effects and state characteristics. In the first two columns, we run panel regressions that include firm, time and state fixed effects and cluster standard errors around state, which account for possible correlation within state. In the first regression, we show that adding state fixed effects to a panel regression where standard errors are clustered around state does not change the results obtained in Table 4 . The coefficient of 0.8 for asymmetric attention is statistically and economically significant. In the second regression, we introduce state characteristics such as GDP per capita to control for richer states and population to control for the size of the state. The magnitude and significance of the asymmetric attention coefficient remains unchanged with respect to previous regressions. The coefficients for both state characteristics are not significant. In the third regression, we report a regression using the Fama MacBeth (1973) method that includes state fixed effects, state GDP per capita and state population. The magnitude and significance of the coefficient for asymmetric attention is similar to the one reported in Table 3 . In sum, the results are robust to state fixed effects and state characteristics for both panel and cross-sectional regressions.

We next check the robustness of our results to industry effects. Hou and Robinson (2006) reported a relation between industry concentration and stock returns. In the fourth regression of Table 6, we run a panel regression with firm, monthly and industry fixed effects and cluster standard errors around industries, which account for possible correlation within industry. We define industry using 2-digit SIC codes. We could use more SIC digits to define an industry, but because we have few firms, as we increase digits, we would then be basically controlling for firm fixed effects, which we have already reported. The magnitude and significance of the asymmetric attention coefficient remains unaltered with respect to results reported in Table 4 . In the fifth regression, we report the Fama and MacBeth (1973) regression with industry fixed effects. The magnitude and significance of the coefficient for asymmetric attention is similar 
to the one reported in Table 3.

Overall, the relation between asymmetric attention and future stock returns is not explained by state characteristics and industry effects.

\section{Liquidity and Asymmetric Attention}

In this section, we aim to explore the causes of the persistence in the asymmetric attention effect. Under the rational agent framework, the relation between asymmetric attention and future returns for the S\&P 500 stocks represents an arbitrage opportunity. Following Fang and Peress (2009) and Garcia and Norli (2010), we conjecture two possibilities for the persistence in this arbitrage opportunity: i) "impediments-to-trade" or "illiquidity" hypothesis suggests that the return differential reflects limits to arbitrage due to trade impediments and $i i$ ) "risk premium" hypothesis suggests that the return differential reflects the pricing of some risks that have not been captured in the analysis. The impediments-to-trade hypothesis will hold if the return differential between the high-asymmetry and no-asymmetry portfolios is more pronounced for the most illiquid stocks. Otherwise, we will conclude that the risk premium hypothesis holds.

We investigate the persistence in the asymmetric attention effect by sorting stocks by the Amihud (2002) liquidity measure. Each month, we sort stocks into quintiles based on the Amihud measure. In each of these liquidity quintiles, we then form three portfolios sorted by asymmetric attention. Specifically, we form a high-asymmetry portfolio, a no-asymmetry portfolio and a long-short portfolio as detailed in the previous section. We form these three portfolios for every liquidity quintile every month and calculate the following-month return for each portfolio. In Table 7, we report both equal-weighted and value-weighted next-month excess returns over the risk free rate for the three portfolios sorted by asymmetric attention for stocks in the first and fifth liquidity quintiles. For robustness, we also report the next-month DGTW abnormal returns for each portfolio.

Table 7 shows that for liquid stocks, the alpha of the high-asymmetry portfolio is 57 bps higher than the one of the no-asymmetry portfolio for equal-weighted excess returns. The 
alpha of the long-short portfolio is, however, not statistically significant different than zero. Instead for illiquid stocks, the alpha for the high-asymmetry portfolio is 70 bps higher than the one for the no-asymmetry portfolio. Also, the alpha of the long-short portfolio is economically and statistically significant. We reach a similar conclusion if we look at the value-weighted excess returns or if instead we focus on risk-adjusted returns.

The results in Table 7 present strong support for the impediments-to-trade hypothesis. The magnitude of the alphas in the long-short portfolios is much higher for most illiquid stocks in both equal-weighted and value-weighted excess returns. Also, the alphas in the longshort portfolios are only statistically significant different than zero for most illiquid stocks. The results are qualitatively similar for the risk-adjusted returns. In sum, Table 7 presents evidence in favor of the limits to arbitrage hypothesis as explanation for the persistence in the asymmetric attention effect.

\section{Information Frictions and Asymmetric Attention}

Our hypothesis throughout the paper is that the asymmetric attention effect is due to information frictions. When investors receive private news about local stocks, according to attention allocation theories, they choose to process more public information about local stocks before making a buying decision. Our conjecture is based on the existence of initial private news. Hence, we should observe that the asymmetric attention effect is more pronounced for stocks headquartered in places where local information is more valuable and difficult to acquire for nonlocals.

We investigate our information frictions conjecture by sorting stocks by remote location. Following, Coval and Moskowitz (2001) and Malloy (2005), we define remote location as the minimum distance between the city where the stock is headquartered and the 21 most populated cities in U.S. We use 21 cities instead of 20 as in previous literature because Boston became the 20th most populated city in 2009 instead of Baltimore. We obtain data on population by city from the U.S. Census Bureau. We then find latitude and longitude data for the headquarters of all stocks in our sample and the 21 most populated cities from U.S. Census 
Bureau's Gazetteer Files. We finally calculate the minimum distance (arc length) between all stocks' headquarters and 21 most populated cities to construct our remote location variable. Our information frictions hypothesis will hold if the return differential between the high-asymmetry and no-asymmetry portfolios is more pronounced for stocks located in more remote places.

Each month, we sort stocks into quintiles based on remote location. For each quintile, we form three portfolios sorted by asymmetric attention: a high-asymmetry portfolio, a noasymmetry portfolio and a long-short portfolio. We form these three portfolios for every remote location quintile every month and calculate the following-month return for each portfolio. In Table 8, we report both equal-weighted and value-weighted next-month excess returns over the risk free rate for the three portfolios sorted by asymmetric attention for stocks in the first and fifth remote location quintiles. For robustness, we also report the next-month DGTW abnormal returns for each portfolio.

Table 8 provides evidence in support of our information frictions conjecture. The asymmetric attention effect is more evident for stocks located in more remote locations where local information is more worthy. The asymmetric attention effect is weak for stocks included in the first remote quintile. These are stocks located in the 21 most populated cities, where private information is difficult to survive. The magnitude of the Jensen's alpha in the high-asymmetry portfolio is always higher than the one for the no-asymmetry portfolio for equal-weighted and value-weighted returns. However, the long-short portfolio alpha is not statistically significant. For stocks located in remote locations, we find economically and statistically significant alphas in the long-short portfolio for both raw and DGTW abnormal equal-weighted or valueweighted returns. For instance, for the value-weighted raw excess returns case, we find an alpha of 82 bps for the long-short portfolio. Overall, Table 8 exhibits evidence in support of the information frictions hypothesis to explain the asymmetric attention effect documented in this paper.

It is important to remark that is not only the presence of information frictions by itself that generate abnormal stock returns as implied by Coval and Moskowitz (2001) and Ivkovic 
and Weisbenner (2005), but also the asymmetric attention effect. They argue that stocks headquartered in remote areas suffer from more asymmetric information, but they are not able to tell when private news arrive. They are only able to form portfolios by stocks, managers or households independently from the month. However, we exploit attention allocation theories to predict when local private news arrive and, in turn, when stocks in remote areas will actually earn higher returns. Specifically, we are able to form portfolios by stock and month.

\section{Conclusion}

In this paper, we exploit the implications of attention allocation theories to form portfolios that generate abnormal stock returns. Stocks earn higher returns when they receive high asymmetric attention. We used two different attention allocation theories. First, following Barber and Odean (2008), we conjectured investors allocate attention to stocks when making buying decisions, but not when making selling decisions. Second, following Van Nieuwerburgh and Veldkamp, (2009) and Mondria and Wu, (2010), we conjectured that investors process more public information about local stocks when they receive private news. We provided strong support for attention allocation theories under different statistical approaches and obtained statistically and economically significant results. Specifically, portfolios formed with stocks that receive high asymmetric attention obtain 46 bps higher next-month returns than portfolios formed with stocks that have no asymmetric attention. We also provided evidence that the asymmetric attention effect is persistent due to limits to arbitrage. Finally, we concluded that the asymmetric attention effect exists due to the presence of local information frictions.

As implied by Coval and Moskowitz (2001), if we form portfolios sorted by remote location of stock headquarters, we obtain higher returns for stocks located in remote areas due to the presence of information frictions. In this paper, however, we are able to tell when those stocks located in remote areas will actually earn higher returns. In particular, for stocks located in remote areas, if we form portfolios sorted by asymmetric attention, we obtain statistically and economically significant alphas. Overall, we provide evidence in strong support for attention 
allocation theories.

Unfortunately, we are not able to increase the sample size of this study to include other stocks. We were not able to perform this analysis due to lack of SVI data at the local level for stocks outside S\&P 500. We conjecture that the asymmetric attention effect will increase in its magnitude because S\&P 500 stocks are widely followed at the national level.

We hope to encourage more work exploiting attention allocation theories in the future. Previous work has focused on the existence of information asymmetries to tackle many finance issues and puzzles. Attention allocation theories allow us to predict the arrival of private information by observing investors' behavior. Thus, given that we can infer the arrival of private news at any moment in time, we can now provide more accurate evidence in favour or against asymmetric information as the explanation to any finance anomaly.

\section{References}

[1] Amihud, Y., 2002. Illiquidity and stock returns: Cross-section and time-series effects. Journal of Financial Markets 5, 31-56.

[2] Bae, K., Stulz, R., Tan, H., 2008. Do local analysts know more? A cross-country study of the performance of local analysts and foreign analysts. Journal of Financial Economics $88,581-606$.

[3] Barber, B., Odean, T., 2008. All That Glitters: The Effect of Attention and News on the Buying Behavior of Individual and Institutional Investors. Review of Financial Studies $21,785-818$.

[4] Carhart, M., 1997. On Persistence in Mutual Fund Performance. Journal of Finance 52, $57-82$.

[5] Coval, J., Moskowitz, T., 1999. Home bias at home: local equity preference in domestic portfolios. Journal of Finance 54, 2045-2073. 
[6] Coval, J, Moskowitz, T., 2001. The Geography of Investment: Informed Trading and Asset Prices. Journal of Political Economy 109, 811-841.

[7] Cremers, M., Petajisto, A., Zitzewitz, E., 2010. Should Benchmarks Indices Have Alpha? Revisiting Performance Evaluation. Working Paper.

[8] Da, Z., Engelberg, J., Gao, P., 2010. In Search of Attention. Forthcoming in Journal of Finance.

[9] Daniel, K., Grinblatt, M., Titman, S., Wermers, R., 1997. Measuring Mutual Fund Performance with Characteristic-Based Benchmarks. Journal of Finance 52, 1035-58.

[10] Davis, J., Fama, E., French, K., 2000. Characteristics, Covariances, and Average Returns: 1929-1997. Journal of Finance 55, 389-406.

[11] Fama, E., French, K., 1993. Common Risk Factors in the Returns on Stocks and Bonds. Journal of Financial Economics 33, 3-56.

[12] Fama, E., MacBeth, J., 1973. Risk, return and equilibrium: empirical tests. Journal of Political Economy 81, 607-636.

[13] Fang, L., Peress, J., 2009. Media coverage and the cross-setion of stock returns. Journal of Finance 64, 2023-2052.

[14] Garcia, D., Norli, O., 2010. Geographic Dispersion and Stock Returns. Working Paper.

[15] Grote, M. and M. Umber, 2006. Home biased? A Spatial Analysis of the Domestic Merging Behavior of US Firms. Working Paper.

[16] Hou, K., Peng, L., Xiong, W., 2008. A tale of two anomalies: The implications of investor attention for price and earnings momentum. Working Paper.

[17] Hou, K., Robinson, D., 2006. Industry Concentration and Average Stock Returns. Journal of Finance 61, 1927-1956. 
[18] Ivkovich, Z., Weisbenner, S., 2005. Local Does As Local Is: Information Content of the Geography of Individual Investors' Common Stock Investments. Journal of Finance 60, $267-306$.

[19] Kacperczyk, M., Van Nieuwerburgh, S., Veldkamp, L., 2010. Rational Attention Allocation over the Business Cycle. Working Paper.

[20] Lou, D., 2008. Attracting Investor Attention through Advertising. Working Paper.

[21] Malloy, C., 2005. The Geography of Equity Analysis. Journal of Finance 60, 719-755.

[22] Mondria, J., Wu, T., 2010. The Puzzling Evolution of the Home Bias, Information Processing and Financial Openness. Journal of Economic Dynamics and Control 34, 875896.

[23] Mondria, J., Wu, T., Zhang, Y., 2010. The Determinants of International Investment and Attention Allocation: Using internet search query data. Journal of International Economics 82, 85-95.

[24] Pastor, L., Stambaugh, R., 2003. Liquidity risk and expected stock returns. Journal of Political Economy 111, 642-685.

[25] Portes, R., Rey, H., 2005. The Determinants of Cross Border Equity Flows. Journal of International Economics 65, 269-296.

[26] Uysal, V., Kedia, S., Panchapagesan, V., 2008. Geography and acquirer returns. Journal of Financial Intermediation 17, 256-275.

[27] Van Nieuwerburgh, S., Veldkamp, L., 2009. Information Immobility and the Home Bias Puzzle. Journal of Finance 64, 1187-1215. 


\section{Table 1: Summary Statistics on Asymmetric Searches}

Search volume index (SVI) of a company is the aggregate search volume for the company's ticker obtained from Google Insights for Search. National searches is the SVI for each company's ticker among search engine users located in U.S. Local searches is the SVI for each company's ticker among search engine users located in the state where the company is headquartered. The asymmetric searches variable is defined as local searches/national searches. Panel A presents the summary statistics for local searches, national searches and asymmetric searches variables. Panel B presents the relation of our asymmetric searches variable to the following firm characteristics: i) ME is the market capitalization in the previous month (t-1); ii) $\mathrm{BE} / \mathrm{ME}$ is the book-to-market value of equity, where the book value, which is calculated according to Davis, Fama, and French (2000), is divided by the previous month market capitalization; iii) RET is the return of the stock during the month; iv) RET[t-13,t-2] is the cumulative return of the stock between t-13 and t-2; v) AMIHUD is the liquidity measure constructed according Amihud (2002); vi) SPREAD is the proportional quoted bid-ask spread; vii) VOLATILITY is the standard deviation of the daily stock returns of the current month; viii) $\triangle$ TURNOVER is the difference in the natural logarithm of stock turnover between $\mathrm{t}$ and $\mathrm{t}-1$. Each month, the sample is divided into five quintiles according to the asymmetric searches variable, where the first quintile consists of stocks with the lowest asymmetric searches. Panel B reports the averages of the firm characteristics for each of the five quintiles.

\section{PANEL A: Descriptive Statistics}

\begin{tabular}{lcccccc} 
& $\begin{array}{c}\text { Number of } \\
\text { Stocks }\end{array}$ & Mean & Std. Dev. & Min. & Median & Max. \\
\hline National searches & 513 & 39.3 & 24.9 & 1 & 37 & 100 \\
Local searches & 486 & 54.6 & 21.4 & 1 & 56 & 100 \\
Asymmetric searches & 486 & 2.3 & 3.3 & 0.04 & 1.24 & 81 \\
\hline \hline
\end{tabular}

PANEL B: Averages by Asymmetric Searches Quintiles

\begin{tabular}{lccccc} 
& 1 & 2 & 3 & 4 & 5 \\
\hline Asymmetric searches & 0.76 & 1.03 & 1.26 & 1.84 & 6.43 \\
ME & 18751.5 & 21996.6 & 20452.3 & 29216.2 & 25705.1 \\
BE/ME & 0.5 & 0.58 & 0.57 & 0.48 & 0.45 \\
RET & 0.88 & 1.04 & 1074 & 0.62 & 0.8 \\
RET[t-13,t-2] & 10.8 & 9.9 & 5.04 & 5.55 & 5.17 \\
AMIHUD & 0.014 & 0.025 & 0.029 & 0.184 & 0.221 \\
SPREAD & 0.133 & 0.146 & 0.137 & 0.127 & 0.111 \\
VOLATILITY & 2.29 & 2.3 & 2.33 & 2.47 & 2.26 \\
$\Delta$ TURNOVER & 0.006 & 0.001 & 0.013 & 0.017 & 0.004 \\
\hline
\end{tabular}




\section{Table 2: Summary Statistics on Asymmetric Attention}

Search volume index (SVI) of a company is the aggregate search volume for the company's ticker obtained from Google Insights for Search. National attention is the abnormal SVI to the company's ticker filtered by searches located in U.S. We define abnormal SVI as (log) SVI during the current month minus the (log) median SVI during the previous quarter (previous three months). We define local attention as the abnormal SVI to the company's ticker filtered by searches located in the state where the company is headquartered. We measure asymmetric attention as the abnormal SVI by locals minus abnormal SVI by average U.S. investor. Panel A presents the summary statistics for our local attention, national attention and asymmetric attention variables. Panel B exhibits the relation of our asymmetric attention variable to the following firm characteristics: i) ME is the market capitalization in the previous month (t-1); ii) $\mathrm{BE} / \mathrm{ME}$ is the book-to-market value of equity, where the book value, which is calculated according to Davis, Fama, and French (2000), is divided by the previous month market capitalization; iii) RET is the return of the stock during the month; iv) RET[t-13,t-2] is the cumulative return of the stock between t-13 and t-2; v) AMIHUD is the liquidity measure constructed according Amihud (2002); vi) SPREAD is the proportional quoted bid-ask spread; vii) VOLATILITY is the standard deviation of the daily stock returns of the current month; viii) $\triangle$ TURNOVER is the difference in the natural logarithm of stock turnover between $t$ and $t-1$. Each month, we divide our sample in five quintiles according to the asymmetric attention variable, where the first quintile consists of stocks with the lowest asymmetric attention. Panel B reports the averages of the firm characteristics for each of the five quintiles.

PANEL A: Descriptive Statistics

\begin{tabular}{lccccc}
\hline \multicolumn{7}{c}{ PANEL A: Descriptive Statistics } & & \\
\hline & Mean & Std. Dev. & Min. & Median & Max. \\
\hline National attention & 0.007 & 0.21 & -3.93 & 0 & 2.71 \\
Local attention & -0.0004 & 0.25 & -3.61 & 0 & 2.52 \\
Asymmetric attention & -0.009 & 0.21 & -2.54 & -0.002 & 3.21 \\
\hline \hline
\end{tabular}

PANEL B: Averages by Asymmetric Attention Quintiles

\begin{tabular}{lccccc} 
& 1 & 2 & 3 & 4 & 5 \\
\hline Asymmetric attention & -0.291 & -0.077 & -0.004 & 0.067 & 0.262 \\
ME & 19441.95 & 25612.2 & 27078.8 & 24527.8 & 20187.8 \\
BE/ME & 0.54 & 0.5 & 0.52 & 0.5 & 0.56 \\
RET & 0.75 & 0.59 & 0.78 & 1.09 & 0.67 \\
RET[t-13,t-2] & 7.17 & 6.44 & 6.04 & 6.32 & 6 \\
AMIHUD & 0.155 & 0.097 & 0.035 & 0.082 & 0.119 \\
SPREAD & 0.121 & 0.128 & 0.132 & 0.148 & 0.134 \\
VOLATILITY & 2.36 & 2.26 & 2.36 & 2.36 & 2.42 \\
DTURNOVER & -0.0001 & -0.0033 & 0.0057 & 0.014 & 0.013 \\
\hline
\end{tabular}




\section{Table 3: Asymmetric Attention and Stock Returns: Fama-MacBeth (1973) regressions}

Table 3 presents monthly Fama and MacBeth (1973) cross-sectional regressions from January 2004 to December 2009. In the first four regressions, the dependent variable is the DGTW characteristic-adjusted abnormal returns from month $\mathrm{t}+1$. Asymmetric searches is defined as the SVI for each company's ticker among search engine users located in the state where the company is headquartered divided by the SVI of users located in U.S. National attention is the abnormal SVI to the company's ticker filtered by searches located in U.S. Abnormal SVI as (log) SVI during the current month minus the (log) median SVI during the previous quarter (previous three months). Local attention is the abnormal SVI to the company's ticker filtered by searches located in the state where the company is headquartered. Asymmetric attention is the abnormal SVI by locals minus abnormal SVI by average U.S. investor. All SVI related variables are calculated for month $t$. All regressions control for the following firm characteristics: $\log (\mathrm{ME})$ is the natural logarithm of the market capitalization in month $\mathrm{t}$; $\log (\mathrm{BE} / \mathrm{ME})$ is the natural logarithm of the book-to-market value of equity, where the book value, which is calculated according to Davis, Fama, and French (2000), is divided by the previous month market capitalization; RET is the return of the stock during month $t$; RET[t-13,t-2] is the cumulative return of the stock between $\mathrm{t}-13$ and $\mathrm{t}-2$; AMIHUD is the liquidity measure constructed according to Amihud (2002) from month $t$; SPREAD is the proportional quoted bid-ask spread in month t; VOLATILITY is the standard deviation of the daily stock returns of the current month $t$; $\triangle$ TURNOVER is the difference in the natural logarithm of stock turnover between $\mathrm{t}$ and $\mathrm{t}-1$. In the fifth regression, the independent variable is raw stock returns at month $\mathrm{t}+1$.

\begin{tabular}{|c|c|c|c|c|c|}
\hline & (1) & (2) & (3) & (4) & $(5)$ \\
\hline Asymmetric searches & $\begin{array}{c}0.017 \\
(0.024)\end{array}$ & & & & \\
\hline National attention & & $\begin{array}{l}-0.25 \\
(0.34)\end{array}$ & $\begin{array}{l}-0.39 \\
(0.28)\end{array}$ & & \\
\hline Local attention & & & $\begin{array}{c}0.72 * * \\
(0.28)\end{array}$ & & \\
\hline Asymmetric attention & & & & $\begin{array}{c}0.63 * * \\
(0.27)\end{array}$ & $\begin{array}{c}0.57 * * \\
(0.26)\end{array}$ \\
\hline $\log (\mathrm{ME})$ & $\begin{array}{c}-0.096^{*} \\
(0.049)\end{array}$ & $\begin{array}{c}-0.09^{*} \\
(0.05)\end{array}$ & $\begin{array}{l}-0.079 \\
(0.048)\end{array}$ & $\begin{array}{l}-0.07 \\
(0.04)\end{array}$ & $\begin{array}{r}-0.19 * * \\
(0.09)\end{array}$ \\
\hline $\log (\mathrm{BE} / \mathrm{ME})$ & $\begin{array}{c}0.154^{*} \\
(0.088)\end{array}$ & $\begin{array}{c}0.12 \\
(0.07)\end{array}$ & $\begin{array}{l}0.16^{*} \\
(0.08)\end{array}$ & $\begin{array}{c}0.17 * * \\
(0.08)\end{array}$ & $\begin{array}{c}0.18^{*} \\
(0.1)\end{array}$ \\
\hline RET & $\begin{array}{c}0.022 \\
(0.014)\end{array}$ & $\begin{array}{c}0.015 \\
(0.013)\end{array}$ & $\begin{array}{c}0.017 \\
(0.014)\end{array}$ & $\begin{array}{c}0.018 \\
(0.014)\end{array}$ & $\begin{array}{c}0.024 \\
(0.016)\end{array}$ \\
\hline $\mathrm{RET}[\mathrm{t}-13, \mathrm{t}-2]$ & $\begin{array}{r}-0.0009 \\
(0.006)\end{array}$ & $\begin{array}{c}-0.002 \\
(0.006)\end{array}$ & $\begin{array}{c}-0.001 \\
(0.006)\end{array}$ & $\begin{array}{c}-0.001 \\
(0.006)\end{array}$ & $\begin{array}{l}-0.001 \\
(0.008)\end{array}$ \\
\hline AMIHUD & $\begin{array}{c}0.505 \\
(0.346)\end{array}$ & $\begin{array}{c}0.18 \\
(0.14)\end{array}$ & $\begin{array}{l}0.59^{*} \\
(0.31)\end{array}$ & $\begin{array}{l}0.59^{*} \\
(0.32)\end{array}$ & $\begin{array}{c}0.46 \\
(0.33)\end{array}$ \\
\hline SPREAD & $\begin{array}{c}0.44 \\
(0.74)\end{array}$ & $\begin{array}{c}0.65 \\
(0.66)\end{array}$ & $\begin{array}{c}0.58 \\
(0.77)\end{array}$ & $\begin{array}{c}0.61 \\
(0.76)\end{array}$ & $\begin{array}{c}0.75 \\
(0.82)\end{array}$ \\
\hline VOLATILITY & $\begin{array}{c}0.005 \\
(0.178)\end{array}$ & $\begin{array}{l}0.056 \\
(0.17)\end{array}$ & $\begin{array}{c}0.03 \\
(0.17)\end{array}$ & $\begin{array}{c}0.04 \\
(0.17)\end{array}$ & $\begin{array}{c}0.05 \\
(0.21)\end{array}$ \\
\hline$\triangle$ TURNOVER & $\begin{array}{c}0.13 \\
(0.16)\end{array}$ & $\begin{array}{c}0.08 \\
(0.16)\end{array}$ & $\begin{array}{c}0.11 \\
(0.16)\end{array}$ & $\begin{array}{c}0.11 \\
(0.17)\end{array}$ & $\begin{array}{c}0.23 \\
(0.15)\end{array}$ \\
\hline R-Squared & 0.08 & 0.07 & 0.08 & 0.08 & 0.12 \\
\hline
\end{tabular}




\section{Table 4: Asymmetric Attention and Stock Returns: Panel regressions}

Table 4 presents panel regressions. The dependent variable is the DGTW characteristic-adjusted abnormal returns in regressions (1)-(4) and raw returns in (5) evaluated at month $t+1$. Asymmetric searches is defined as local searches/national searches. National attention and local attention are the abnormal SVI to the company's ticker filtered by searches located in U.S and searches located in the state where the company is headquartered respectively. Asymmetric attention is defined as local attention minus national attention. All SVI related variables are calculated for month t. All regressions control for the following firm characteristics: $\log (\mathrm{ME})$ is the natural logarithm of the market capitalization in month $\mathrm{t}$; $\log (\mathrm{BE} / \mathrm{ME})$ is the natural logarithm of the book-to-market value of equity; RET is the return of the stock during month $t$; RET[t-13,t-2] is the cumulative return of the stock between $t-13$ and $t-2$; AMIHUD is the liquidity measure from Amihud (2002) at month $t$; SPREAD is the proportional quoted bid-ask spread at month $\mathrm{t}$; VOLATILITY is the standard deviation of the daily stock returns at month $\mathrm{t}$; $\triangle$ TURNOVER is the log difference of stock turnover between $t$ and $t-1$. We include monthly and firm fixed effects in all panel regressions. All regressions report heteroskedasticity-robust standard errors. In the fifth regression, standard errors are also clustered within firm.

$(1)$

Asymmetric searches

0.003

$(0.08)$

National attention

Local attention

Asymmetric attention

$\log (\mathrm{ME})$

$\log (\mathrm{BE} / \mathrm{ME})$

RET

$\operatorname{RET}[\mathrm{t}-13, \mathrm{t}-2]$

AMIHUD

SPREAD

VOLATILITY

$\triangle T$ TURNOVER
(2)

$-0.16$

$(0.27)$

(3)

(3)

$-0.59$

$0.86 * *$

(0.32)

\begin{tabular}{lccccc} 
& $(0.12)$ & $(0.1)$ & $(0.12)$ & $(0.12)$ & $(0.1)$ \\
\hline Monthly Fixed Effects & YES & YES & YES & YES & YES \\
Firm Fixed Effects & YES & YES & YES & YES & YES \\
Clusters (Firms) & NO & NO & NO & NO & YES \\
\hline R-Squared & 0.03 & 0.03 & 0.03 & 0.03 & 0.03 \\
\hline
\end{tabular}

$0.8^{* *} \quad 0.8^{* *}$

(0.3) $\quad(0.3)$

$-3.4 * * \quad-3.4 * *$

(0.26) (0.39)

$1.7 * * \quad 1.7 * *$

$(0.21) \quad(0.21)$

$0.01 \quad 0.01$

$(0.009) \quad(0.009)$

$0.005^{*} \quad 0.005^{*}$

$(0.003) \quad(0.003)$

$0.06 \quad 0.06^{* *}$

$(0.05) \quad(0.004)$

$0.03 \quad 0.03$

$(0.13) \quad(0.13)$

$-0.14 \quad-0.14$

$(0.11) \quad(0.11)$

$0.04 \quad 0.04$

$-0.14$

(0.11) 


\section{Table 5: Excess Return on Portfolios Sorted by Asymmetric Attention}

Table 5 exhibits the Jensen's alphas for portfolios sorted by asymmetric attention and portfolios sorted by local attention. Local attention is the abnormal SVI to the company's ticker filtered by searches located in the state where the company is headquartered. Asymmetric attention is local attention minus national attention. Panel A presents the factor loadings and Jensen's alpha for the equal-weighted and value-weighted returns of all stocks. Panel B exhibits the alphas for the three portfolios sorted by asymmetric attention. Each month, we form three different portfolios: i) high-asymmetry portfolio consists of stocks with asymmetric attention above the 80th percentile; ii) no-asymmetry portfolio consists of stocks that are not included in the high-asymmetry portfolio; iii) long-short portfolio is a zeroinvestment portfolio that longs high-asymmetry stocks and shorts no-asymmetry stocks. We calculate the followingmonth excess return over the risk free rate for each portfolio and regress the time-series excess returns on the fivefactor model that includes the three Fama and French factors, the momentum factor and the liquidity factor. We also report the alphas when we calculate the next-month DGTW abnormal returns for each portfolio. Panel C presents the Jensen's alphas for three portfolios sorted by local attention.

PANEL A: Factor Loadings and Jensen's Alpha for S\&P 500 Constituents

\begin{tabular}{lcccccc} 
& Alpha & Mkt-Rf & SMB & HML & MOM & LIQ \\
\cline { 1 - 4 } All Firms & & & & & & \\
EW Excess Returns & $0.3^{* *}$ & $1.05^{* *}$ & $0.23^{* *}$ & 0.04 & $-0.14^{* *}$ & 1.04 \\
& $(0.07)$ & $(0.03)$ & $(0.04)$ & $(0.04)$ & $(0.02)$ & $(2.9)$ \\
VW Excess Returns & 0.03 & $0.95^{* *}$ & $-0.11^{* *}$ & 0.006 & -0.025 & $-5.05^{* *}$ \\
& $(0.05)$ & $(0.02)$ & $(0.02)$ & $(0.025)$ & $(0.022)$ & $(1.5)$ \\
\hline Firms with Local Attention & & & & & & \\
\hline \multirow{2}{*}{ EW Excess Returns } & $0.3^{* *}$ & $1.05^{* *}$ & $0.28^{* *}$ & 0.05 & $-0.1 * *$ & 3.1 \\
& $(0.09)$ & $(0.03)$ & $(0.05)$ & $(0.05)$ & $(0.03)$ & $(3.53)$ \\
VW Excess Returns & 0.09 & $0.95^{* *}$ & $-0.14^{* *}$ & -0.001 & 0.034 & $-4.5^{* *}$ \\
& $(0.06)$ & $(0.02)$ & $(0.03)$ & $(0.034)$ & $(0.027)$ & $(2.1)$ \\
\hline \hline
\end{tabular}

PANEL B: Excess Return on Portfolios Sorted by Asymmetric Attention

\begin{tabular}{lccccccc} 
& \multicolumn{3}{c}{ Raw Returns } & \multicolumn{3}{c}{ Risk-Adjusted Returns } \\
\cline { 2 - 7 } & No-asym & High-asym & High-No & No-asym & High-asym & High-No \\
\hline \multirow{3}{*}{ EW Excess Returns } & $0.21^{* *}$ & $0.63^{* *}$ & $0.42^{* *}$ & $0.15^{*}$ & $0.4^{* *}$ & $0.25^{*}$ \\
& $(0.09)$ & $(0.17)$ & $(0.14)$ & $(0.08)$ & $(0.12)$ & $(0.12)$ \\
VW Excess Returns & 0.01 & $0.47^{* *}$ & $0.46^{* *}$ & -0.01 & $0.36^{* *}$ & $0.37^{* *}$ \\
\hline \hline
\end{tabular}

PANEL C: Excess Return on Portfolios Sorted by Local Attention

\begin{tabular}{lccc|ccc} 
& \multicolumn{3}{c}{ Raw Returns } & \multicolumn{3}{c}{ Risk-Adjusted Returns } \\
\cline { 2 - 7 } & No-local & High-local & High-No & No-local & High-local & High-No \\
\hline \multirow{3}{*}{ EW Excess Returns } & $0.23^{* *}$ & $0.57^{* *}$ & 0.34 & $0.16^{* *}$ & $0.38^{* *}$ & 0.22 \\
& $(0.09)$ & $(0.25)$ & $(0.26)$ & $(0.08)$ & $(0.18)$ & $(0.2)$ \\
VW Excess Returns & 0.04 & 0.19 & 0.15 & 0.03 & 0.21 & 0.18 \\
& $(0.08)$ & $(0.19)$ & $(0.25)$ & $(0.05)$ & $(0.17)$ & $(0.19)$ \\
\hline
\end{tabular}




\section{Table 6: Asymmetric Attention and Stock Returns: Robustness}

Table 6 presents panel and Fama-MacBeth (1973) regressions, where the dependent variable is the DGTW characteristic-adjusted abnormal returns evaluated at month $\mathrm{t}+1$. This table aims at checking the robustness of the main results of the paper to state and industry effects. Asymmetric attention is defined as local attention minus national attention at month $t$. All regressions control for the following firm characteristics: $\log (\mathrm{ME})$ is the natural logarithm of the market capitalization in month $t ; \log (\mathrm{BE} / \mathrm{ME})$ is the natural logarithm of the book-to-market value of equity; RET is the return of the stock during month $t$; RET[t-13,t-2] is the cumulative return of the stock between t-13 and t-2; AMIHUD is the liquidity measure from Amihud (2002) at month t; SPREAD is the proportional quoted bidask spread at month $t$; VOLATILITY is the standard deviation of the daily stock returns at month $t$; $\triangle$ TURNOVER is the $\log$ difference of stock turnover between $t$ and $t-1$. We include monthly and firm fixed effects in all panel regressions. The first three regressions control for state fixed effects. The second and third regressions control for the following state characteristics: GDP per capita and population. The fourth and fifth equations control for industry fixed effects. We define industry using 2-digit SIC codes.

\begin{tabular}{|c|c|c|c|c|c|}
\hline & $(1)$ & $(2)$ & (3) & (4) & (5) \\
\hline Asymmetric attention & $\begin{array}{c}0.8^{* * *} \\
(0.3)\end{array}$ & $\begin{array}{c}0.8 * * \\
(0.3)\end{array}$ & $\begin{array}{l}0.58 * \\
(0.32)\end{array}$ & $\begin{array}{l}0.8 * * \\
(0.3)\end{array}$ & $\begin{array}{c}0.59^{* *} \\
(0.25)\end{array}$ \\
\hline $\log (\mathrm{ME})$ & $\begin{array}{l}-3.4 * * \\
(0.47)\end{array}$ & $\begin{array}{l}-2.5^{* *} \\
(0.46)\end{array}$ & $\begin{array}{c}0.03 \\
(0.05)\end{array}$ & $\begin{array}{l}-3.4 * * \\
(0.45)\end{array}$ & $\begin{array}{l}-0.02 \\
(0.06)\end{array}$ \\
\hline $\log (\mathrm{BE} / \mathrm{ME})$ & $\begin{array}{l}1.7 * * \\
(0.2)\end{array}$ & $\begin{array}{l}1.6^{* *} \\
(0.2)\end{array}$ & $\begin{array}{l}0.15^{*} \\
(0.09)\end{array}$ & $\begin{array}{l}1.7 * * \\
(0.3)\end{array}$ & $\begin{array}{l}0.13 \\
(0.1)\end{array}$ \\
\hline RET & $\begin{array}{c}0.01 \\
(0.009)\end{array}$ & $\begin{array}{c}0.01 \\
(0.01)\end{array}$ & $\begin{array}{l}0.029^{*} \\
(0.015)\end{array}$ & $\begin{array}{c}0.01 \\
(0.01)\end{array}$ & $\begin{array}{c}0.01 \\
(0.01)\end{array}$ \\
\hline $\operatorname{RET}[\mathrm{t}-13, \mathrm{t}-2]$ & $\begin{array}{c}0.005 \\
(0.003)\end{array}$ & $\begin{array}{c}0.003 \\
(0.003)\end{array}$ & $\begin{array}{c}-0.006 \\
(0.004)\end{array}$ & $\begin{array}{c}0.005 \\
(0.003)\end{array}$ & $\begin{array}{l}-0.002 \\
(0.005)\end{array}$ \\
\hline AMIHUD & $\begin{array}{l}0.06 * * \\
(0.004)\end{array}$ & $\begin{array}{l}0.07 * * \\
(0.009)\end{array}$ & $\begin{array}{c}0.64 \\
(0.39)\end{array}$ & $\begin{array}{l}0.06 * * \\
(0.007)\end{array}$ & $\begin{array}{l}0.52^{*} \\
(0.31)\end{array}$ \\
\hline SPREAD & $\begin{array}{c}0.03 \\
(0.15)\end{array}$ & $\begin{array}{c}0.03 \\
(0.15)\end{array}$ & $\begin{array}{c}0.44 \\
(0.62)\end{array}$ & $\begin{array}{c}0.03 \\
(0.15)\end{array}$ & $\begin{array}{c}0.4 \\
(0.76)\end{array}$ \\
\hline VOLATILITY & $\begin{array}{l}-0.14 \\
(0.08)\end{array}$ & $\begin{array}{l}-0.29 \\
(0.1)\end{array}$ & $\begin{array}{c}-0.1 \\
(0.19)\end{array}$ & $\begin{array}{l}-0.14 \\
(0.09)\end{array}$ & $\begin{array}{l}-0.07 \\
(0.16)\end{array}$ \\
\hline$\triangle T$ TURNOVER & $\begin{array}{c}0.04 \\
(0.08)\end{array}$ & $\begin{array}{c}0.14 \\
(0.09)\end{array}$ & $\begin{array}{c}0.05 \\
(0.17)\end{array}$ & $\begin{array}{c}0.05 \\
(0.14)\end{array}$ & $\begin{array}{c}0.1 \\
(0.15)\end{array}$ \\
\hline Population & & $\begin{array}{l}3.14 \mathrm{e}-07 \\
(2.7 \mathrm{e}-07)\end{array}$ & $\begin{array}{l}8.84 \mathrm{e}-06 \\
1.23 \mathrm{e}-04\end{array}$ & & \\
\hline GDP per Capita & & $\begin{array}{r}-1.00 \mathrm{e}-04 \\
(6.6 \mathrm{e}-05)\end{array}$ & $\begin{array}{l}1.49 \mathrm{e}-09 \\
2.74 \mathrm{e}-08\end{array}$ & & \\
\hline$\overline{\mathrm{OLS}}$ & YES & YES & $\mathrm{NO}$ & YES & $\mathrm{NO}$ \\
\hline Fama-MacBeth (1973) & NO & NO & YES & NO & YES \\
\hline Monthly Fixed Effects & YES & YES & $\mathrm{NO}$ & YES & $\mathrm{NO}$ \\
\hline Firm Fixed Effects & YES & YES & $\mathrm{NO}$ & YES & NO \\
\hline State Fixed Effects & YES & YES & YES & $\mathrm{NO}$ & NO \\
\hline Industry Fixed Effects & NO & NO & NO & YES & YES \\
\hline$\overline{\text { Clusters (State) }}$ & YES & YES & $\mathrm{NO}$ & $\mathrm{NO}$ & $\mathrm{NO}$ \\
\hline Clusters (Industry) & $\mathrm{NO}$ & NO & NO & YES & NO \\
\hline R-Squared & 0.05 & 0.06 & 0.06 & 0.05 & 0.2 \\
\hline
\end{tabular}




\section{Table 7: Excess Return on Portfolios Double Sorted by Asymmetric Attention and Liquidity}

Table 7 exhibits the Jensen's alphas for portfolios double sorted according to asymmetric attention and Amihud (2002) liquidity measure. Asymmetric attention is local attention minus national attention. Each month, we sort stocks into quintiles based on the Amihud measure. In each of these liquidity quintiles, we then form the following three portfolios based on asymmetric attention: i) high-asymmetry portfolio consists of stocks with asymmetric attention above the 80th percentile; ii) no-asymmetry portfolio consists of stocks that are not included in the high-asymmetry portfolio; iii) long-short portfolio is a zero-investment portfolio that longs high-asymmetry stocks and shorts noasymmetry stocks. We form these three portfolios for every liquidity quintile every month and calculate the followingmonth excess return over the risk free rate for each portfolio. We then regress the time-series excess returns on the five-factor model that includes the three Fama and French factors, the momentum factor and the liquidity factor. Table 7 reports the alphas of the five-factor model with both equal-weighted and value-weighted next-month excess returns over the risk free rate for the three portfolios sorted by asymmetric attention for stocks in the first and fifth liquidity quintiles. For robustness, we also report the alphas when we calculate the next-month DGTW abnormal returns for each portfolio.

\begin{tabular}{lccc|ccc} 
& \multicolumn{3}{c|}{ Raw Returns } & \multicolumn{3}{c}{ Risk-Adjusted Returns } \\
\cline { 2 - 7 } & No-asym & High-asym & High-No & No-asym & High-asym & High-No \\
\hline Liquid Stocks & -0.08 & 0.49 & 0.57 & -0.11 & 0.28 & 0.39 \\
\multirow{2}{*}{ EW Excess Returns } & $(0.16)$ & $(0.31)$ & $(0.37)$ & $(0.14)$ & $(0.3)$ & $(0.32)$ \\
& -0.03 & 0.44 & 0.47 & -0.09 & 0.33 & $0.42^{*}$ \\
VW Excess Returns & $(0.14)$ & $(0.29)$ & $(0.36)$ & $(0.07)$ & $(0.22)$ & $(0.24)$ \\
& & & & & & \\
\hline Illiquid Stocks & & & & & & \\
\hline \multirow{2}{*}{ EW Excess Returns } & $0.77^{* *}$ & $1.47^{* *}$ & $0.7^{*}$ & $0.47^{* *}$ & $1.19^{* *}$ & $0.72^{*}$ \\
& $(0.19)$ & $(0.33)$ & $(0.39)$ & $(0.23)$ & $(0.34)$ & $(0.41)$ \\
VW Excess Returns & 0.12 & $1.31^{* *}$ & $1.19^{* *}$ & 0.07 & $0.87^{* *}$ & $0.8^{* *}$ \\
\hline
\end{tabular}




\section{Table 8: Excess Return on Portfolios Double Sorted by Asymmetric Attention and Remote Location}

Table 8 exhibits the Jensen's alphas for portfolios double sorted according to asymmetric attention and remote location. Asymmetric attention is local attention minus national attention. Remote location is the minimum distance between the city where the stock is headquartered and the 21 most populated cities in U.S. Each month, we sort stocks into quintiles based on remote location. In each of these remote location quintiles, we then form the following three portfolios based on asymmetric attention: i) high-asymmetry portfolio consists of stocks with asymmetric attention above the 80th percentile; ii) no-asymmetry portfolio consists of stocks that are not included in the high-asymmetry portfolio; iii) long-short portfolio is a zero-investment portfolio that longs high-asymmetry stocks and shorts noasymmetry stocks. We form these three portfolios for every remote location quintile every month and calculate the following-month excess return over the risk free rate for each portfolio. We then regress the time-series excess returns on the five-factor model that includes the three Fama and French factors, the momentum factor and the liquidity factor. Table 8 reports the alphas of the five-factor model with both equal-weighted and value-weighted next-month excess returns over the risk free rate for the three portfolios sorted by asymmetric attention for stocks in the first and fifth remote location quintiles. For robustness, we also report the alphas when we calculate the next-month DGTW abnormal returns for each portfolio.

\begin{tabular}{lccc|ccc} 
& \multicolumn{3}{c|}{ Raw Returns } & \multicolumn{3}{c}{ Risk-Adjusted Returns } \\
\cline { 2 - 7 } & No-asym & High-asym & High-No & No-asym & High-asym & High-No \\
\hline Metro Stocks & -0.1 & 0.24 & 0.35 & -0.09 & 0.14 & 0.23 \\
\cline { 3 - 7 } EW Excess Returns & $(0.17)$ & $(0.39)$ & $(0.36)$ & $(0.16)$ & $(0.31)$ & $(0.32)$ \\
& -0.29 & -0.12 & 0.17 & $-0.3^{* *}$ & 0.02 & 0.32 \\
VW Excess Returns & $(0.18)$ & $(0.47)$ & $(0.47)$ & $(0.15)$ & $(0.37)$ & $(0.37)$ \\
& & & & & & \\
Remote Stocks & & & & & & \\
\hline \multirow{3}{*}{ EW Excess Returns } & $0.29^{* *}$ & $1.6^{* *}$ & $1.31^{*}$ & 0.14 & $1.39^{* *}$ & $1.25^{* *}$ \\
& $(0.13)$ & $(0.75)$ & $(0.76)$ & $(0.13)$ & $(0.3)$ & $(0.29)$ \\
VW Excess Returns & 0.12 & $0.94^{* *}$ & $0.82^{*}$ & 0.05 & $0.65^{*}$ & $0.6^{*}$ \\
\hline
\end{tabular}

